\title{
Factors influencing on obtaining a light output homogeneous distribution along long-length detectors based on CsI(TI) scintillators
}

\author{
D.I.Zosim \\ Institute for Scintillation Materials, STC "Institute for Single Crystals" \\ National Academy of Sciences of Ukraine, 60 Nauky Ave., 61072 Kharkiv, Ukraine
}

\section{Received September 30, 2017}

The role of matting the long-dimension scintillators based on CsI(Tl) single crystals for achieving a homogeneous distribution of light output along their length was studied. It was shown that the matting of scintillators resulted in developing roughness on their surface and in violating the optical homogeneity which is manifested in the appearance of birefringence bands. It is established that the maximum homogeneity of the distribution of the light output along long-length detectors is achieved due to the interaction of the light of scintillations with the regions of the crystal in which the optical characteristics differ from those in the neighboring space with these regions.

Keywords: CsI(Tl) long-length scintillators, matting, homogeneity of distribution of light output.

Исследована роль матирования длинномерных сцинтилляторов на основе монокристаллов $\mathrm{Csl}(\mathrm{TI})$ в достижении однородного распределения световыхода вдоль их длины. Показано, что матирование сцинтилляторов приводит к образованию шероховатости на их поверхности, а так же нарушению оптической однородности, которое проявляется в возникновении в них полос двулучепреломления. Установлено, что максимальная однородность распределения световыхода вдоль длинномерных детекторов достигается вследствие взаимодействия света сцинтилляций с областями кристалла, в которых оптические характеристики отличаются от аналогичных им в граничащем, с этими областями, пространстве.

Фактори, щодо впливаються на отримання гомогеневого розподільного випромінювання світлочного виготовлення для довгострокових детекторів на основі сцинтлітаторів CsI(TI). Д.I.Зосім

Досліджено роль особливого виду шліфування довгомірних сцинтиляторів на основі монокристалів Csl(TI) в досягненні рівномірного розподілу світлового виходу уздовж їx довжини. Показано, що механічна обробка сцинтиляторів призводить до утворення шорсткості на їх поверхні, а також порушення оптичної однорідності, яке проявляється у виникненні в них смуг двопроменевого заломлення. Встановлено, що максимальна однорідність розподілу світловиходу вздовж довгомірних детекторів досягається внаслідок взаємодії світла сцинтиляцій з ділянками кристалу, в яких оптичні властивості відрізняються від аналогічних їм у просторі, що з ними межує. 


\section{Introduction}

CsI(Tl) scintillators in the form of an irregular truncated pyramid with polished surfaces are characterized by an inhomogeneous distribution of light output along their length. According to results of $[1,2]$, the inhomogeneity of the distribution of the activator in the crystal bulk cannot be the reason of the effect [3] if only the local values of concentration do not exceed the limits of the "plateau" on the dependence of light output concentration. In the case where the inhomogeneity of the light output distribution is a factor limiting the practical application of scintillators $[4,5]$, it is removed by matting the crystals by abrasive materials [6]. The purpose of this treatment is to create a roughness on the surface of the crystal. This method is based on the notion that the interaction of the light rays of scintillations with the surface roughness increases the probability of their getting to the photo-detector [7,8]. Meanwhile, in the experiment, with constant parameters of matting, the reproducibility of the homogeneity values of the light output distribution is comparatively low from sample to sample, cut out even from one single-crystal boule. This effect can be a consequence of that under the matting of crystals, processes are activated which contribution to the change in light-gathering predominates over the contribution of the mechanisms of interaction of scintillation light with a roughness.

\section{Experimental}

The CsI (Tl) crystals were grown by an automated seed drawing method in a conical crucible [9]. "Samples-witnesses" in the form of a rectangular parallelepiped with a length of $4.5 \mathrm{~cm}$ and a cross-section of $1.1 \mathrm{~cm} \times 2.3 \mathrm{~cm}$ were cut from the layer of boules along their generatrix by directional dissolution in water [10]. These samples were used for qualitative and quantitative control of the composition of impurities in crystals by optical and IR spectroscopy. The concentration of the activator impurity in boules was in the interval of values of 0.04 to $0.14 \mathrm{~mol} \%$. The content of uncontrolled impurity molecular anions does not exceed $3 \times 10^{-5} \mathrm{~mol} \%$. Billets in the form of an irregular truncated pyramid with a length of $17 \mathrm{~cm}$, bases $1.53 \times 2.93 \mathrm{~cm}^{2}$ and $2.27 \times 4.55 \mathrm{~cm}^{2}$, as well as ones with a length of $18 \mathrm{~cm}$ and bases $1.53 \times 2.93 \mathrm{~cm}^{2}$ and $2.31 \times 4.46 \mathrm{~cm}^{2}$ were cut on the lathe. After machine processing, the scintillators were ground and then polished.

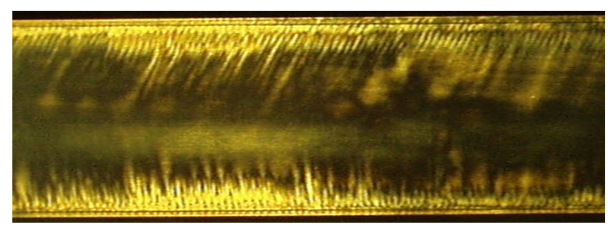

Fig. 1 Photograph of the area of the matted crystal CsI (TI) $(\Delta=0.48 \%)$ in polarized light.

The need for such processing is justified in [11]. In grinding and polishing operations, ethylene glycol $\left(\mathrm{C}_{2} \mathrm{H}_{6} \mathrm{O}_{2}\right)$ was used as the wetting liquid. The homogeneous distribution of the light output along the length of the pyramids was obtained by matting the crystal surfaces with F400 grinding paper without the use of wetting liquids. For measurements of the light output (Ly) and the amplitude resolution $(R)$ of the pyramids, they were placed in the outer reflective envelope of VM3M. Then, the pyramids were placed with a large base on an optical membrane based on sylgard 184 with thickness $0.13 \mathrm{~cm}$, which was located directly on the photomultiplier. In the experiments we used a Hamamatsu R1306 photomultiplier with maximum photocathode sensitivity $\lambda_{\max }=420 \mathrm{~nm}\left(L y=L y_{b}\right)$ and Hamamatsu R669 with $\lambda_{\max }=600 \mathrm{~nm}\left(L y=L y_{r}\right)$. The distribution of $L y$ along the scintillators was measured by collimation of the $\gamma$-rays from the ${ }^{137} \mathrm{Cs}$ radionuclide.

The homogeneity of the distribution of the light output along the length of the pyramids $(\Delta)$ was determined from the relation $\Delta=\left(L y_{\max }-L y_{\min }\right) / L y_{\text {ave }} 100 \%$, where $L y_{\text {max }}, L y_{\text {min }}, L y_{\text {ave }}$ are maximum, minimum and average $L y$ values in the data array obtained by scanning the samples; $L y_{\text {ave }}=\frac{1}{N} \cdot \sum_{m} L y_{m}, N$ is the number of points along the crystal, in which the light output was measured. In studies of the $R(E)$ dependence, noncollimated sources of ${ }^{57} \mathrm{Co}$, ${ }^{22} \mathrm{Na}$ and ${ }^{137} \mathrm{Cs}$ radiation were used which were located at a distance equal to two of their lengths from the crystals. The distributions of the pulse amplitudes obtained from scintillators when excited by $\gamma$-photons were recorded with a Sugan spectrometer [12].

\section{Results and discussion}

In polarized light, birefringence bands are observed in a matted crystal (Fig.1). This effect indicates that matting, as a method of obtaining roughness, causes the appearance of areas in the crystals where their optical homogeneity is impaired. 


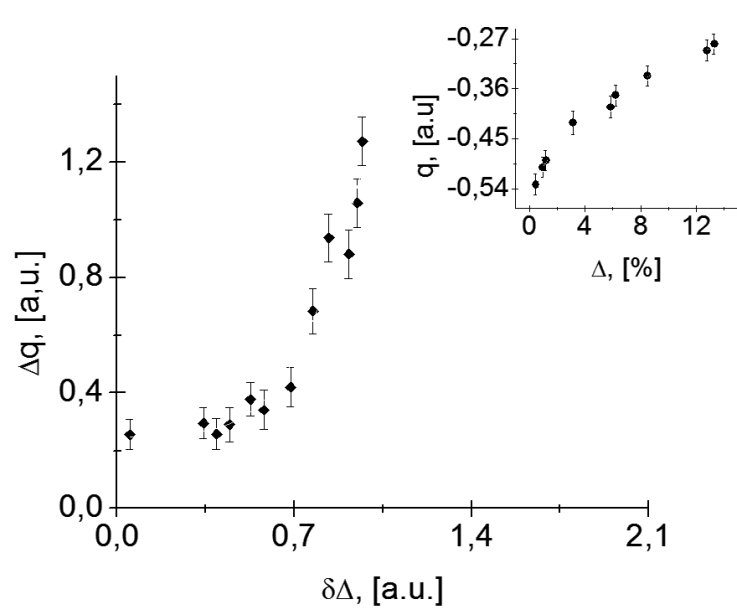

Fig.2. Correlation between the increment of the exponent $\delta q$ and the value $\delta \Delta$ for CsI(TI) scintillators in the form of an irregular truncated pyramid.

In this case, the probability that light from scintillations hits the photo-detector is determined by the interaction of scintillation light both with the surface roughness and with the areas of the crystal where optical inhomogeneities are present. The contributions of each of the mechanisms to the value of $\Delta$ are proposed to be divided by analyzing the dependence of $R$ on $E$, or, which is the same, $R$ on $L y$. The essence of the approach is as follows: the interaction of scintillation light with a roughness causes a change in the light-gathering $(\tau)$ only; its interaction with areas with optical inhomogeneities leads to variations of $\tau$ that correlate with a conversion efficiency ( $\eta$ ) change initiated by violations of the structural perfection of scintillators. Because of this, the dependence of $R$ on $L y$, which has the form $\mathbf{R} \sim L y^{-q}$, obeys different laws [13] which correspond to different values of the exponent $q$. The growth of real crystals leads to inhomogeneities both in $\tau$ and $\eta$ values. Their contributions to the investigated processes were taken into account by comparing the results of measurements of experimental samples and "specimen-witnesses". The latter were cut from the same sections of the boules as the experimental samples but were not subjected to any machining. The results of the experiments are shown in Fig. 2 in the form of the dependence of $\delta q$ on $\delta \Delta$, where $\delta q=$ $\left(q_{g r}-q_{\mathrm{o}}\right) / q_{\mathrm{o}}, \quad \delta \Delta=\left(\Delta_{p}-\Delta_{g r}\right) / \Delta_{p}, q_{\mathrm{o}}$ and $q_{g r}$ are values $q$ for "samples-witnesses" and crystals in the form of a pyramid after matting, $\Delta_{p}$ and $\Delta_{g r}$ are values $\Delta$ for pyramids

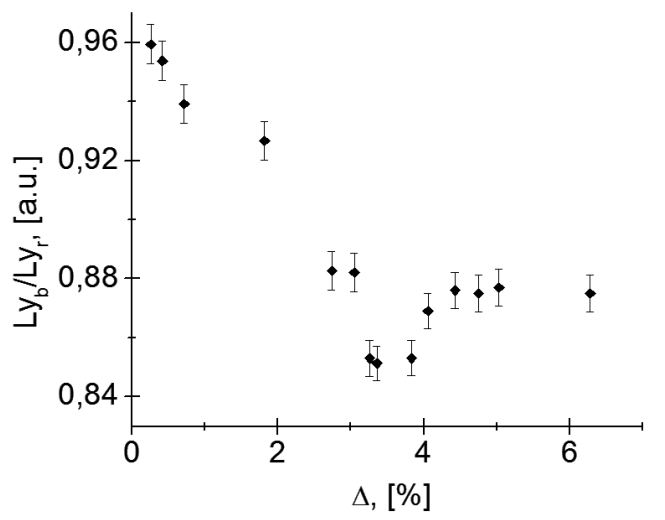

Fig.3. Correlation between the values of $\Delta$ and the $L y_{b} / L y_{r}$ ratio in Csl (TI) crystals in the form of an irregular truncated pyramid.

with polished and matted surfaces. The inset in Fig. 2 shows the typical character of the $q_{g r}$ behavior, which is caused by the matting of the crystals; the corresponding "samples-witnesses" have the values $q_{o} \approx 0.28 \pm 0.01$. The scattering of the experimental data in Fig. 2 can arise due to the instability of the spectral matching coefficient of the $\mathrm{Csl}(\mathrm{TI})$ radioluminescence $(R L)$ spectra with the spectral sensitivity $\left(Q_{\lambda}\right)$ of the photomultiplier cathode to the concentration gradient of the activator (TI) in the scintillators. This effect is due to the fact that as the $C_{\mathrm{Tl}}$ increases in the boundaries where $L y\left(C_{\mathrm{Tl}}\right)=$ const, the width of the CsI(TI) RL spectrum $\left(\sigma_{\lambda}\right)$ decreases at a rate of $\sim 546$ $\mathrm{nm} / \mathrm{mol} \%$, while $Q_{\lambda}$ of the photomultiplier R1306 decreases with a speed $\sim 0.39 \mathrm{~mA} / \mathrm{W} \cdot \mathrm{nm}$ with growing (within $\sigma_{\lambda}$ ). Analogous measurements carried out on the photomultiplier R669 show a 2.9 times smaller scatter in the data, since in this case, $Q_{\lambda}$ parameter increases with the velocity $\sim 0.14 \mathrm{~mA} / \mathrm{W} \mathrm{nm}$ with increasing $\lambda$ within $\sigma_{\lambda}$. It was found that the decrease in long truncated pyramids is accompanied by a change in the $L y_{b} / L y_{r}$ ratio in Fig.3.

Matting of the surface of crystals changes the relief of the interface between crystal and air media and, as can be seen from Fig. 1, induces birefringence bands in crystals.

This means that the matting of the scintillators will lead to a change in the lightgathering, not only because of the scintillation light scattering by the rough surface, but also through its propagation through the regions of the crystal whose optical characteristics differ from those analogous to them in the neighboring volume with 
these regions. Despite this, the dependence of $R$ on $E$ must obey the law $R \sim E^{-1 / 4}$, as it follows from calculations [14]; the experimental confirmation is presented in [15]. Meanwhile, experiments with long-length detectors have shown that as a result of matting this dependence is not observed. A possible reason for this is that when the crystals are machined, structural defects appear in their near-surface regions. They can penetrate into the volume of the crystal and interact not only with the crystal lattice (Fig. 1), but also with each other and with impurities. As a result, the inhomogeneities in the $\eta$ distribution appear [16], which lead to an increase in the spread of the pulse amplitudes at the output of the spectrometer, and, as a consequence, to a deviation from the $R \sim E^{-1 / 4}$ type relationship. These inhomogeneities are caused by the formation of regions in the bulk of crystals in which $\eta$ differs from the values in the crystal volume bordering with them. Authors [13] discriminate these areas by the ratio of their sizes $(d)$ to the maximum path (l) of a secondary electron. They showed that for macroscopic inhomogeneities $(d / l>1)$ the relation $R \sim E^{-1 / 4}$ is still valid, whereas for micro inhomogeneities $(d / l<1)$ this relation is in the form $R \sim E^{-1 / 2}$. The value of $l$ is determined by the concentration of the scattering centers, the cross section of their interaction with the electron and by the temperature of the medium $[17,18]$. This makes it possible to assume that the exponent of $q$ can take a continuous series of values from $\sim-1 / 4$ to $\sim-1 / 2$ depending on the degree of crystal perfection. In accordance with accepted assumptions, it can be concluded that structural defects begin to occupy the crystals already at the stage of their machine processing. This is confirmed by the results of the experiments presented in Fig. 2, from which it can be seen that in the polished pyramids $(\Delta>9 \%)$ the q value does not become zero. The monotonous change in the index $q$ from $-1 / 4$ to $-1 / 2$ observed with decreasing $\Delta$ (the inset in Fig. 2) reflects the increasing contribution to $R$ of the interaction processes of $\gamma$-photons with micro-inhomogeneities. This is confirmed by a change in the ratio between the light output values $L y_{b}$ and $L y_{r}$ which can be determined by measuring scintillators in photomultipliers with different quantum sensitivity of photo-cathodes (Fig. 3). The reason for this phenomenon is that the intensities of the "blue" and "green" components in the CsI(TI) $R L$ spec- tra are determined both by the content of $C_{\mathrm{Tl}}$ and by the concentrations of impurity vacancy and vacancy dipoles [19] which are sensitive to the crystal structure perfection [20]. Thus, the matting of crystals should lead to an increase in $R$ due to increasing the contribution related with the interaction between $\gamma$-photons and micro-inhomogeneities. Another mechanism for increasing $R$, initiated by matting consists in reducing due to the scattering of scintillation light by a rough surface. In [21] it is noticed that a homogeneous distribution of light output is achieved with light output losses. This follows from the equation for $\tau$ [21], in which the scattering quantity is taken into account by the factor $t=e^{-\mu H}$, where $H$ is the distance from the scintillation location to the photodetector, $\mu=k+s, k$ and $s$ are the absorption and scattering coefficients, respectively. In the experiment, meanwhile, the opposite phenomenon is observed, consisting in decreasing $R$ as $\Delta$ decreases. Consequently, there is an effective mechanism that dominates the processes of $R$ increase. It follows from the structure of the equation for $\tau$ that this mechanism should be responsible for the increase of the aperture angle. The magnitude of this angle is determined by the refractive index of the crystal, the local values of which, as it follows from the presence of birefringence bands, change under the influence of mechanical treatment. The verification of this assumption consisted in measuring the $L y$ values and $\Delta_{g r}$ for scintillators with a roughness obtained as a result of matting, and after its removal. The experiments showed that for pyramids with $\Delta_{g r} \leq 3 \%$, the removal of roughness leads to deviation of Ly and $\Delta_{g r}$ from those obtained with a rough surface by an amount not exceeding $\pm 0.03 \%$. The thickness of the layer removed by polishing is $\sim 130 \mu \mathrm{m}$.

\section{Conclusions}

Achievement of homogeneous distribution of light output along long-length pyramids based on CsI (TI) single crystals by matting their surfaces is provided by lightgathering changes, which are caused by the formation of regions in crystals where optical inhomogeneities are induced by treatment. Birefringence bands and inhomogeneity of conversion efficiency in scintillators are created, when matted, by the same type of structural defects. 


\section{References}

1. R.B.Murray, A.Mayer. Phys.Rew.,122, 15, 1961. 2. Bondarenko S. et al. Nucl. Instrum. Meth. A486, 474, 2002

3. A. Wagner et.al. Nucl. Instrum. Meth. A456, $290,2001$.

4. Stefan Diehl, Kai-Thomas Brinkmann et al. 17th Int. Conf. Calorimetr. Particle Physics (CALOR2016). IOP Conf. Series Journal of Physics: Conf. Series, 928, 012040, 2017. doi :10.1088/1742-6596/928/1/012040

5. Martin Gascon, Hector Alvarez-Pol, Sebastien Ancelin et all. Characterization of Large Frustum CsI(Tl) Crystals for the R3B Calorimeter. IEEE Trans. Nuclear Scie., 56, 962, 2009.

6. M.-J. van Goethem, M.S. Wallace et al. Nucl. Instr. Meth. A 526, 455, 2004

7. Patent USA 3102955

8. M.E.Globus, B.V.Grinyov. Inorganic scintillators , Kharkov, AKTA Publ., 2000, P.402 [in Russian].

9. V.I.Gorileckij, B.V. Grinev, B.G. Zaslavskij, Rost Kristallov [Crystal Growth]. Kharkov, AKTA Publ., 2002, P.535 [ in Russian]

10. V.I.Goryletskiy, Instr. Exper. Techn., 43, 2, 2000.
11. Kudin A.M. et al. Vopr. Atom. Nauki Techn. 80, 111, 2001.

12. http://www.sugan.com.ua

13. Yu.A.Cirlin, E.P. Mohir, Monokristalli, scintillatori, I organicheskie lyuminofori. Kharkov. Monokristall., 1,67, 1967.

14. J.Sharpe, IRE Transaction, NS-7, 2-3, 44, 1960.

15. Yu.A.Nemilov, et al. Izv. AN SSSR. ser. Fizika, 23, 1959.

16. P.Lecoq, A. Gektin, M. Korzhik. Inorganic Scintillators for Detector Systems: Physical Principles and Crystal Engineering. Springer International Publishing Switzerland, 2017.

17. O.Madelung. Introduction to solid-state theory. Translated by B.C.Taylor. Springer-Verlag Berlin Heidelberg New York. 1978.

18. Liapidevskii V.K. Metodi detectirovanija izluchenii. M. Energoatomizdat.1987, P.408.

19. V.D. Alekseyev, L.N. Trefilova i dr. Izv. VUZ. Fizika.1-2, 12, 2011.

20. V. Savenko, E. D. Shchukin, Colloid Journal. 69, 782, 2007.

21. Yu.A.Cirlin, Cvetosobiranie v scintillacionnih schetchikah, Atomizdat, M., 1975. 